\title{
A NATUREZA E O GAÚCHO HERÓI NAS TRAMAS DA HISTÓRIA: TENSIONAMENTOS FOUCAULTIANOS
}

\author{
Nature and Heroic Gaucho in tangles of history: \\ Foucauldian stresses
}

\author{
Virgínia Tavares Vieira* \\ Paula Corrêa Henning **
}

\begin{abstract}
RESUMO
O presente artigo tem como objetivo colocar em evidência o conceito de História do Presente e Genealogia, a partir dos estudos do filósofo francês Michel Foucault. Nossa proposta está em problematizar a emergência de saberes, que atrelados a relações de força, vem fabricando uma natureza marcada por ideal de beleza e romantismo no Pampa do Rio Grande do Sul. Demarcamos ainda condições de emergência para constituição de um sujeito gaúcho tomado como herói a partir de alguns acontecimentos históricos e da música pampeana. Apoiadas no pensamento de Michel Foucault, problematizamos a fabricação de um espaço geográfico e cultural marcado pela beleza, pela fartura - por glórias e façanhas. Vale tensionar a história problematizando como relações saber-poder nos fabricam enquanto sujeitos pampeanos contemporâneos. É no desejo de tensionar verdades estabelecidas que nos subjetivam enquanto sujeitos fabricados e imiscuídos nas tramas da história que este texto foi escrito. Políticas de formação e subjetividades gaúchas merecem um olhar cuidadoso e provocativo.
\end{abstract}

* Graduada em Música e Mestre e Doutoranda em Educação Ambiental pela Universidade Federal do Rio Grande - FURG. Participante e pesquisadora do Grupo de Pesquisa em Educação, Cultura, Ambiente e Filosofia (GEECAF) - FURG. Professora substituta do curso de Licenciatura em Música da Universidade Federal de Pelotas - UFPel.

** Doutora em Educação. Professora Associada da Universidade Federal de Rio Grande - FURG. Professora no PPG Educação Ambiental e Educação em Ciências da mesma instituição. Coordenadora e pesquisadora do Grupo de Pesquisa em Educação, Cultura, Ambiente e Filosofia (GEECAF) - FURG. 
Palavras chave: Michel Foucault; História do Presente; Música Pampeana.

\begin{abstract}
The aim of this paper is to put in evidence the concept of the History of Present and Genealogy, starting from studies of the French philosopher Michel Foucault. Our proposal is in the problematization of the emergency of knowledge that, together with relations of strength, is creating a natural environment known for the idea of beauty and romanticism in the Pampa of Rio Grande do Sul. We demarcated, also, the conditions of emergency for the constitution of a gaucho individual seen as a hero since historical events and pampeana music. Based on Michel Foucault's ideas, we problematized the elaboration of a geographic and cultural space known for its beauty, abundance, glories, and achievements. It is worth to stress the history when problematizing how relations between knowledge and power make the contemporary pampeano individual. It is in the intention of stressing established truths, which lead to a subjectivity of the individual constituted and involved in tangles of history, that this paper was written. Politics of gaucho formations and subjectivities deserve a careful and serious observation.
\end{abstract}

Keywords: Michel Foucault; History of Present; Pampeana Music.

\title{
Primeiras palavras
}

[...] o começo histórico é baixo. Não no sentido de modesto ou de discreto como o passo da pomba, mas derrisório, de irônico, próprio a desfazer todas as enfatuações. ${ }^{1}$

Tomamos as palavras de Foucault ${ }^{2}$ para assentar a escrita deste artigo que tem como objetivo colocar em evidência o conceito de história a partir dos estudos de Michel Foucault. Na citação acima, Foucault ressalva que o começo histórico é "baixo, irônico". 
Aproximando-se de Friedrich Nietzsche, isto seria compor uma história vista de baixo, uma história das margens, dos desvios, dos saberes imperfeitos. A História do Presente, da qual Nietzsche e Foucault nos falam, é uma história preocupada com as singularidades, com as dispersões e acasos. Ou seja, a história da Proveniência e da Emergência.

O Rio Grande do Sul é marcado por inúmeras guerras e revoluções que contribuíram significativamente para a constituição do povo gaúcho e, também, para a cultura do pampa gaúcho, partilhada por muitos sujeitos que vivem no Rio Grande. Vale ressaltar que, neste texto, não nos interessa discorrer sobre cada guerra ou revolução, e desta forma, traçar uma linha contínua e ordenada da história de nosso Estado. A história que aqui se faz, diferentemente da história tradicional, é selecionada e recortada pelos olhos do historiador - ou seja, pelo nosso olhar de pesquisadores. É preciso buscar nos rastros, nas descontinuidades, nas rupturas do pensamento "detectar a incidência das interrupções" "3. Assim, o retorno ao passado está em apreender as condições de possibilidade para a constituição de determinados saberes atrelados a relações de força que nos produziram e nos constituem enquanto sujeitos na contemporaneidade, fabricados que somos pelos diferentes atravessamentos e formações que nos subjetivam.

[...] a história do pensamento, dos conhecimentos, da filosofia, da literatura, parece multiplicar as rupturas e buscar todas as perturbações da continuidade, enquanto a história propriamente dita, a história pura, parece apagar, em benefício das estruturas fixas, a irrupção dos acontecimentos. $^{4}$

3 FOUCAULT, Michel. A arqueologia do saber. Trad. Luiz Felipe Baeta Neves. Rio de Janeiro: Forense Universitária, 2012, p.4.

4 FOUCAULT, Michel. A arqueologia do saber. Trad. Luiz Felipe Baeta Neves. Rio de Janeiro: Forense Universitária, 2012, p. 6-7. 
A história genealógica problematizada por Foucault não se transporta de forma unidimensional, cíclica, na tentativa de revelar as certezas de uma época. Rompe-se com a história totalizante, de produção da verdade, de progresso, a fim de tensionar os fatos. A questão fundamental é apreender como alguns acontecimentos e conceitos são fabricados numa relação intrínseca entre vida e linguagem. É preciso compreender que tais conceitos são produzidos por nós, em diferentes momentos históricos. A invenção de discursos torna-se artefatos que produzem sentidos em nossas vidas ao determinar coisas e constituir sentidos, fabricando verdades em cada período de nossa história.

A História, tomada sob uma perspectiva arqueológica, à maneira de Foucault, não pode ser jamais um saber íntegro ou vinculado à essência dos seres desdobrados em trans-historiadores. Foucault nos ensina a pensar no limite da revelação e do ocultamento, da visibilidade e da invisibilidade, instâncias que se tornam mais eloquentes na medida em que elevadas a um estado de exaustão de seus significados. ${ }^{5}$

A história arqueológica da qual o autor discorre são ferramentas analíticas utilizadas por Foucault na sua primeira fase, a qual foi denominada arqueologia. Neste método de análise o autor problematizava como se constituíam os saberes a partir de uma escavação vertical nas camadas incontínuas de discursos já proferidos. Nesta medida, tornava-se possível evidenciar a forma como se constituíam conceitos, ideias e discursos muitas vezes já esquecidos. A fase arqueológica tinha/tem como preceito compreender como nos tornamos aquilo que somos enquanto sujeitos de saber. Assim, Foucault estava preocupado com as condições de possibilidade para a fabricação de determinados discursos, sociais, Fortaleza, v. 42, n.2, jul/dez, p. 108-118, 2011, p.117. 
pretendendo apontar o solo epistemológico em que certos saberes emergiram.

Ao chegar em sua segunda fase de estudos, a Genealogia, o autor não abandona a Arqueologia; ele faz, isto sim, um deslocamento metodológico onde o foco não está somente no nível do próprio discurso, mas também no campo extradiscursivo. Nesta modificação, Michel Foucault passa a interessar-se pelas relações políticas do poder, as relações saber/poder.

Em nosso estudo problematizamos a emergência de saberes atrelados a relações de força na fabricação de uma natureza demarcada por ideal de beleza e romantismo, bem como na fabricação de um sujeito gaúcho herói. Ressaltamos que não buscamos a origem, tampouco a explicação desses ditos, mas sim as condições de possibilidade para a emergência desses saberes referentes à natureza. Tratamos de trazer à tona alguns acontecimentos da história e músicas pampeanas, que guardam familiaridades e descrições do modo de ser da vida campeira, da vida do gaúcho e das suas relações com a natureza. A partir disso, compreendemos que, em alguma medida, vamos sendo atravessados e capturados por determinadas formações discursivas que produzem um determinado tipo de vida e de relação com a natureza - um determinado tipo de sujeito. Assim, ao circular na cultura, essas formações discursivas potencializam uma produção de sentido e significados constituindo um modo de ser sujeito. São verdades produzidas pela cultura que vão construindo modos de ser, viver e de pensar. Interessa a partir de uma perspectiva foucaultiana compreender como nos tornamos aquilo que somos. Ou seja, como vamos acolhendo um determinado tipo de existência numa relação intrínseca com o poder. Para Foucault ${ }^{6}$ o poder funciona como um mecanismo de força que nos subjetiva, na qual os indivíduos se tornam resultados dessas relações. Queremos falar aqui dessa subjetivação gaúcha, de um modo de ser sujeito na sua relação com a natureza no desejo de tensionar verdades estabelecidas que nos fabricam enquanto sujeitos imiscuídos nas tramas da história. Nesse

6 FOUCAULT, Michel. Diálogo sobre o poder. In: Ditos \& Escritos IV; organização e seleção de textos MOTTA, Manoel Barros da; Trad. Vera Lucia Avellar Ribeiro. Rio de Janeiro: Forense Universitária, 2010. 
sentido, políticas de formação e subjetividades gaúchas merecem um olhar cuidadoso e provocativo.

\section{História, tensionamentos e subjetividades gaúchas nas tramas da natureza}

A natureza romantizada pela música pampeana ${ }^{7}$, foi/é apontada por alguns artefatos culturais e pela historiografia como uma natureza "selvagem", a qual o homem deveria dominar. Questões assim ficam evidentes também em algumas letras de música no século XIX, como mostra a canção "O Gaúcho", publicada no livro Gargalhadas em 1889.

Eu sou gaúcho d'America! / Filho orgulhoso dos pampas, / Devastei todas as rampas, estribado na razão! / Repontando os infinitos, / Montado nos pensamentos, / Com a justiça nos tentos / Não temi a escravidão [...]. ${ }^{8}$

Olhar para esta canção do século XIX dá ênfase à necessidade que temos de conhecer as condições históricas que possibilitaram a fabricação de determinados saberes. Ou seja, vale compreendermos quais práticas e quais discursos permitiram a emergência de saberes referentes à natureza e a subjetividade gaúcha. A letra da canção nos apresenta um sujeito que enaltece este pertencimento a terra pampeana de forma orgulhosa, no entanto, em nome da razão e sem medo da escravidão, desbrava a natureza. O que

7 A música pampeana ou latino-americana é um estilo musical que compreende os países da América Latina. Aqui nos interessa olhar para os ritmos latino-americanos que constituem parte da cultura gaúcha, a partir de gêneros como a milonga, o chamamé, a canção, a chimarrita, etc. editores, 1889 , p.10.

8 OS EDITORES. Gargalhadas. $2^{\mathrm{a}}$ ed. Pelotas e Porto Alegre: Echenique \& Irmão 
nos parece interessante é mostrar o paradoxo nas formas de narrar este pertencimento à paisagem natural e cultural pampeana. Ora, ao mesmo tempo em que o sujeito sente orgulho de ser um gaúcho d'América, dos pampas, deste "vasto tapete verde de sedutoras campinas" " 9 , como muitas vezes os campos sulinos são descritos, ele desbrava a natureza. Esta música datada de dois séculos atrás retrata um gaúcho "guerreiro", sem medo de lutar por sua terra. Conforme Cezimbra Jacques ${ }^{10}$, a poesia dos Cancioneiros sul-rio-grandenses era marcada de um fiel sentimento de amor dos namoradores, de ciúmes, de desprezo e gratidão; mas também tinha na sua compleição "o valor guerreiro; a expansão do ódio e da vingança, da sinceridade e da amizade, a sátira, a crítica, a expressão da atividade pastoril e militar [...] e cheias, muitas vezes, de elevação moral" "11. Já a canção abaixo, composta entre o período de 1835 e 1845, nos mostra como a natureza pampeana era descrita.

Tens a campina grandiosa debaixo do céu azul / A minha pátria formosa / Belo Rio Grande do Sul. Tens a campina grandiosa cheia de encanto e luxo, / Sobre esta terra gloriosa, / Por façanhas do Gaúcho! Tens a campina grandiosa, / Onde a lida guerreira, / A Farrapada gloriosa, / Legou-nos hino e bandeira! / Tens no hino e na bandeira, / Legado de galhardia, / Que na bela União Brasileira, / Traduz a tua autonomia. Tens a campina grandiosa, / Tens um povo lutador, / Tens a paisana mimosa, / Cheia de graça e primor. / Tens a campina grandiosa, / E nas florestas verdejantes, / Bela fruta saborosa / Quadrúpedes, aves galantes. Tens na campina grandiosa, / Serrania fecunda, / Onde a colheita é viçosa, / Onde o alimento abunda [...]. ${ }^{12}$

9 JACQUES, João Cezimbra. Assuntos do Rio Grande do Sul. Porto Alegre: União de Seguros Gerais, 1979, p.24.

10 João Cezimbra Jacques (1849-1922) foi um militar brasileiro precursor do Movimento Tradicionalista Gaúcho e fundador do Grêmio Gaúcho de Porto Alegre em 1898.

11 JACQUES, João Cezimbra. Assuntos do Rio Grande do Sul. Porto Alegre: União de Seguros Gerais, 1979, p.40.

12 JACQUES, João Cezimbra. Assuntos do Rio Grande do Sul. Porto Alegre: União de Seguros Gerais, 1979, p.144. 
O fragmento acima discorre sobre o Rio Grande do Sul, sobre as "belezas naturais" que compõem o cenário do pampa. Céu azul, campina grandiosa e formosa tomada de muito encanto e luxo, onde isso tudo nos beneficia com o resultado de uma terra abundante. Esta terra também é gloriosa por façanhas do gaúcho farrapo: guerreiro na luta, mas também na difícil lida campeira.

Olhar a história nos auxilia, decisivamente, nesta tarefa de pensar a constituição da subjetividade gaúcha na sua articulação com a natureza. De acordo com Revel ${ }^{13}$, o termo história aparece frequentemente nas obras de Michel Foucault. O filósofo francês se aproxima deste conceito ao estudar a obra de Friedrich Nietzsche. Ou seja, seguindo esta linha de argumentação, a história não deveria ser concebida como evolutiva, linear, ou contínua, onde pudéssemos encontrar uma origem (Ursprung). Desta forma, afasta-se de um conceito de história tradicional para uma história que busca nas rupturas e nos rastros do pensamento apreender as verdades fabricadas. O interessante está em entender de que forma se dá a fabricação de saberes que não estiveram desde sempre ai! Ou seja, ao invés de buscarmos a origem desses saberes e quando se deu a fabricação deste homem herói dos pampas, tentaremos mostrar como se fabrica no cerne da história um sujeito "[...] que é a cada instante fundado e refundado pela história" ${ }^{14}$. Isso seria romper/abandonar a ideia de origem e pensar em consonância com Nietzsche e Foucault. Lançar um olhar para o Pampa gaúcho e para a história do Rio Grande do Sul, não com o objetivo de “"memorizar' os monumentos do passado", mas sim, buscar "transformá-los em documentos" 15.

Nietzsche criticava a história monumental e supra-histórica 16. A recusa a uma pesquisa de origem está no entendimento de que não há uma essência das coisas, uma verdade verdadeira que estivesse aí para ser descoberta, imóvel e precedente a tudo que fosse externo, acidental. É por isso que o filósofo ressalta a importância de se

13 REVEL, Judith. Dicionário Foucault. Trad. Anderson Alexandre da Silva. Rio de Janeiro: Forense Universitária, 2011.

14 FOUCAULT, Michel. A verdade e as formas jurídicas. Trad. Eduardo Jardim e Roberto Machado. Rio de Janeiro: Nau, 2013, p.20.

15 FOUCAULT, Michel. A arqueologia do saber. Trad. Luiz Felipe Baeta Neves. Rio de Janeiro: Forense Universitária, 2012, p. 8.

16 FOUCAULT, Michel. Microfísica do Poder. Rio de Janeiro: Edições Graal, 2011. 
escutar a história ao invés de acreditar na metafísica. O autor salienta, ainda, que o segredo talvez seja apreender que a "essência" é fabricada e que, diante disso, a história nos ensina "[...] a rir das solenidades de origem" ${ }^{17}$. Pois, "Procurar uma tal origem é tentar reencontrar 'o que era imediatamente', 'o aquilo mesmo', de uma imagem exatamente adequada a si" ${ }^{18}$. O mais importante nesse tipo investigação é a possibilidade de compreender que discursos, que práticas foram se constituindo a partir de determinadas condições sociais, políticas, econômicas e culturais que na contemporaneidade aparecem como uma verdade universal. A História do Presente busca compreender a produção de discursos no seu cruzamento com o poder. Seguindo na mesma linha de argumentação, trata-se de entender que a fabricação desses saberes é efeito de um entrecruzamento entre práticas e ditos. É na proliferação dos acontecimentos, nos mais variados começos, que dado objeto "surge", ou melhor, "ascende". Assim,

[...] a palavra discurso ocorre tão naturalmente para designar o que é praticado. Foucault não revela um discurso misterioso, diferente daquele que todos nós temos ouvido: unicamente, ele nos convida a observar, com exatidão, o que assim é dito. Ora, essa observação prova que a zona do que é dito apresenta preconceitos, reticências, saliências e reentrâncias inesperadas de que os locutores não estão, de maneira nenhuma, conscientes. ${ }^{19}$

Assim, ao invés de partirmos dos universais, dos grandes acontecimentos (embora eles também sejam visitados), nos parece mais importante compreender que as práticas constituem "[...] $\mathrm{o}$

17 FOUCAULT, Michel. Microfísica do Poder. Rio de Janeiro: Edições Graal, 2011, p.18. 18 FOUCAULT, Michel. Microfísica do Poder. Rio de Janeiro: Edições Graal, 2011, p.17. 19 VEYNE, Paul. Como se escreve a história; Foucault revoluciona a história. Trad. Alda Baltar e Maria AuxiadoraKneipp. $4^{\text {a }}$ Ed. Brasília: Editora Universidade de Brasília, 2008, p. 252. 
conjunto da história que as faz ser", ou seja, "as coisas, os objetos não são senão os correlatos da prática" ${ }^{20}$.

O que efetivamente interessa nesse modo de fazer pesquisa, de pensar a história, é compreender que séries podem ser estabelecidas para que a natureza, assim como a vida campeira do Rio Grande do Sul, passasse a ser cantada, pintada, ilustrada, entoada com tanta veemência na arte sul-rio-grandense. Nosso ensaio estará em "buscar definir, no próprio tecido documental, unidades, conjuntos, séries, relações" ${ }^{21}$. Ou seja, é preciso buscar nos documentos o que é dito sobre o homem, o gaúcho, a natureza. Como a natureza é descrita na música pampeana? Que acontecimentos atrelados a relações de força deram a ver o aparecimento da natureza na música em suspenso? De que forma cultura e natureza se atravessam, se articulam? Quais as relações do gaúcho com a natureza apresentada nas letras de música em análise? Que conexões se pode estabelecer entre a natureza e as diferentes revoluções em que o Rio Grande do Sul lutou para a constituição de um sujeito gaúcho, marcado pela sua heroicidade?

Seguindo na mesma linha argumentativa, onde a história não é entendida como memória e sim como genealogia, é possível dizermos, então, que a análise histórica seria "a condição de possibilidade de uma ontologia crítica do presente" ${ }^{22}$. Sendo assim, a fim de entender como se constituíram esses saberes, precisaremos mapear as proveniências como condições de possibilidade para a emergência do que hoje é dito sobre a natureza e o sujeito gaúcho herói. Em termos metodológicos, torna-se importante compreender os "[...] processos pelos quais os indivíduos se tornam sujeitos como resultado de um intrincado processo de objetivação que se dá no interior de redes de poderes, que os capturam, dividem,

20 VEYNE, Paul. Como se escreve a história; Foucault revoluciona a história. Trad. Alda Baltar e Maria AuxiadoraKneipp. $4^{\text {a }}$ Ed. Brasília: Editora Universidade de Brasília, 2008, p. 256.

21 FOUCAULT, Michel. A arqueologia do saber. Trad. Luiz Felipe Baeta Neves. Rio de Janeiro: Forense Universitária, 2012, p. 8.

22 REVEL, Judith. Dicionário Foucault. Trad. Anderson Alexandre da Silva. Rio de Janeiro: Forense Universitária, 2011, p. 80. 
classificam". ${ }^{23}$ De acordo ainda com o autor, a pesquisa da proveniência se dá em terrenos movediços, ou seja, em um chão complexo. Assim, é preciso ir aos documentos não na tentativa de buscar verdades históricas, mas estilhaços que porventura foram deixados de fora da história tradicional. Examinar os documentos não significa fazer outra interpretação para colocar diferentes verdades em evidências. A questão é problematizar as múltiplas explicações que chegam até nós como verdades inquestionáveis, entendendo-as como inventadas e não como descobertas. O que fica claro é que a genealogia se apresenta como um desenho de investigação que visa encontrar nos percalços, nas descontinuidades, nas singularidades dos acontecimentos, aquilo que de certa forma não partilha da história. Para Veiga-Neto ${ }^{24}$ seria nesse momento de suas pesquisas que $\mathrm{o}$ filósofo francês passaria a se interessar efetivamente no "poder enquanto elemento capaz de explicar como se produzem os saberes e como nos constituímos na articulação entre ambos". É com tal preocupação que buscaremos analisar as letras de música, por nós, pacientemente coletadas. Ou seja, com a intenção de entender que discursos, que saberes e que verdades sobre a natureza na região sulina do Brasil foram sendo constituídas, a partir de determinadas condições sociais, políticas, econômicas e culturais. Diferentemente de uma pesquisa pautada na linearidade da história, nos grandes acontecimentos, onde se pressupõe desvendar as verdades de nosso tempo, esta pesquisa buscará apreender como se constituem esses saberes atravessados por relações de força. Uma investigação que se assentará "no acoplamento dos conhecimentos eruditos e das memórias locais" 25 . Aproximar-se deste pensamento implica entender que tais jogos de força possibilitam a emergência de determinados saberes referentes à natureza pampeana, bem como a constituição de um sujeito gaúcho "herói" que tem na sua compleição

23 VEIGA-NETO, Alfredo. Algumas raízes da Pedagogia moderna. In: ZORZO, Cacilda; SILVA, Lauraci D \& POLENS, Tamara (org.). Pedagogia em conexão. Canoas: Editora da Ulbra, 2004, p. 65-83, p. 55.

24 VEIGA-NETO, Alfredo. Foucault e a Educação. $2^{\mathrm{a}}$ ed. 1 reimp. Belo Horizonte: Autêntica, 2007, p. 56.

25 FOUCAULT, Michel. Diálogo sobre o poder. In: Ditos \& Escritos IV; organização e seleção de textos MOTTA, Manoel Barros da; Trad. Vera Lucia Avellar Ribeiro. Rio de Janeiro: Forense Universitária, 2010, p. 9. 
as "marcas" dessa natureza. Pois, como nos diz Machado ${ }^{26}$, “o fundamental da análise é que saber e poder se implicam mutuamente: não há relação de poder sem constituição de um campo de saber, como também, reciprocamente, todo saber constitui novas relações de poder".

Para Foucault, a sociedade funciona a partir de relações de poder em constantes transformações. O poder é um mecanismo de força que nos subjetiva, na qual os indivíduos se tornam resultados dessas relações de força.

[...] numa sociedade como a nossa [...] múltiplas relações de poder perpassam, caracterizam, constituem o corpo social; elas não podem dissociar-se, nem estabelecer-se, nem funcionar sem uma produção, uma acumulação, uma circulação, um funcionamento do discurso verdadeiro. Não há exercício do poder sem uma certa economia dos discursos de verdade que funcionam nesse poder, a partir e através dele. Somos submetidos pelo poder à produção da verdade e só podemos exercer o poder mediante a produção da verdade. ${ }^{27}$

$\mathrm{Na}$ esteira do autor interessa compreender como saber e poder se atravessam e se articulam nas formações discursivas que nos subjetivam e nos constituem enquanto sujeitos numa relação inextricável com as questões sociais, políticas, econômicas, culturais. Ainda para o autor, o caráter de uma pesquisa genealógica implica em desnaturalizar saberes e verdades dadas como inquestionáveis. Por isso, a genealogia exige paciência ${ }^{28}$. Esse "modo" de fazer pesquisa permite compreender como emergiram certos conceitos em determinadas épocas atrelados a relações de força, e que na

26 FOUCAULT, Michel. A verdade e as formas jurídicas. Trad. Eduardo Jardim e Roberto Machado. Rio de Janeiro: Nau, 2013, p. xxi.

27 FOUCAULT, Michel. Diálogo sobre o poder. In: Ditos \& Escritos IV; organização e seleção de textos MOTTA, Manoel Barros da; Trad. Vera Lucia Avellar Ribeiro. Rio de Janeiro: Forense Universitária, 2010, p. 22.

28 FOUCAULT, Michel. Microfísica do Poder. Rio de Janeiro: Edições Graal, 2011. 
contemporaneidade são capazes de nos auxiliar a compreender o presente. Aqui a pesquisa genealógica se faz importante a fim de analisar as práticas discursivas e não-discursivas de um determinado tempo social e cultural que deram a ver a invenção de um sujeito tomado por sua heroicidade.

Nesse sentido, trata-se de entender que a fabricação de determinados objetos é efeito de uma multiplicidade de práticas e discursos. Foucault entende o discurso como um "[...] conjunto de enunciados que se apoiem em uma mesma formação discursiva" ${ }^{29} \mathrm{e}$ ressalta ainda que a fabricação dos discursos se dá em um emaranhado de relações históricas, sociais e políticas. Nas palavras do autor:

Eu parto do discurso tal qual ele é! Em uma descrição fenomenológica, se busca deduzir do discurso alguma coisa que concerne ao sujeito falante; tenta-se encontrar, a partir do discurso, quais são as intencionalidades do sujeito falante - um pensamento em via de se fazer. $\mathrm{O}$ tipo de análise que pratico não trata do problema do sujeito falante, mas examina as diferentes maneiras pelas quais o discurso desempenha um papel no interior de um sistema estratégico em que o poder está implicado, e para o qual o poder funciona. ${ }^{30}$

Quando Foucault refere-se ao poder como componente importante nesta maquinaria estratégica que é o discurso, significa que saber e poder se implicam mutuamente. Visto desse modo, o poder, para Foucault (além do mesmo não ser localizado, ou seja, não está centralizado no Estado), não carrega em si um sentido negativo. Pelo contrário: o poder é da ordem do positivo; o poder produz saber! $\mathrm{E}$ os discursos, imersos em relações de poder e saber, fazem ver e

29 FOUCAULT, Michel. A arqueologia do saber. Trad. Luiz Felipe Baeta Neves. Rio de Janeiro: Forense Universitária, 2012, p. 135.

30 FOUCAULT, Michel. Diálogo sobre o poder. In: Ditos \& Escritos IV; organização e seleção de textos MOTTA, Manoel Barros da; Trad. Vera Lucia Avellar Ribeiro. Rio de Janeiro: Forense Universitária, 2010, p. 253. 
falar às práticas sociais que nos constituem enquanto sujeitos de um determinado tempo social e cultural.

Com base nessas concepções é que buscamos analisar, a partir da música pampeana, que enunciações de natureza e de gaúcho apareciam no material colocado sob análise. Que verdades vêm sendo inventadas, fabricadas sobre o Pampa do século XIX para cá e que desempenham um papel importante na história e na cultura desses sujeitos que tanto enaltecem a paisagem natural sulina. Nos interessou compreender que relações de poder e saber se entrelaçam na fabricação da natureza pampeana. E ainda: que acontecimentos sociais, políticos, econômicos, culturais, artísticos e geográficos fizeram desse indivíduo "desertor, andarilho, bêbado, boêmio e mulherengo" ${ }^{31}$ um sujeito herói, gentílico, virtuoso?

Por isso, se faz necessário entender a trama discursiva que vem compondo o cenário típico da vida pastoril dos séculos XVIII e XIX, ainda tão evidente na música e no imaginário do que é o Rio Grande do Sul, o gaúcho em pleno século XXI. É a partir de ditos como esses que nos debruçamos em nosso material de análise, na expectativa de compreender como vêm se constituindo esses discursos sobre a paisagem natural sulina, que atrelados a relações de força, nos constituem enquanto sujeitos gaúchos - de bota $e$ bombacha!. No entanto, quando nos propomos a fazer análise do discurso, não estamos tentando encontrar uma verdade de uma época e/ou de determinadas coisas, pois os discursos não escondem coisas falsas, tampouco verdadeiras, mas simplesmente eles inventam coisas, fabricam verdades. Ainda:

\footnotetext{
"As palavras e as coisas" é o título - sério - de um problema; é o título - irônico - do trabalho que lhe modifica a forma, lhe desloca os dados e revela, afinal de contas, uma tarefa inteiramente diferente, que consiste em não mais tratar os discursos como conjunto de signos (elementos significantes que remetem a conteúdos ou a
}

31 GONÇALVES, Carlos Fernando Poeta; SANTOS, Márcia Belzareno dos. Diferentes olhares sobre a escrita/personalidade gaúcha. Ciência e Conhecimento. Revista eletrônica da Ulbra. São Jerônimo. V. 03, p. 1-12, 2008, p. 3. 
representações), mas como práticas que formam sistematicamente os objetos de que falam. Certamente os discursos são feitos de signos; mas o que fazem é mais que utilizar esses signos para designar coisas. É esse mais que os tornam irredutíveis à língua e ao ato de fala. É esse "mais" que é preciso fazer aparecer e que é preciso descrever. ${ }^{32}$

Seguindo na mesma linha argumentativa, torna-se importante ressaltar que para uma prática discursiva entrar em operação, ela necessariamente deve estar atravessada e sustentada por um conjunto de regras que a tornam evidente. Ou seja, que outros discursos, que enunciações e enunciados dão visibilidade ao discurso em suspenso. Nesse sentido, podemos dizer que o discurso não opera sozinho, ou seja, ele precisa estar apoiado e sustentado por outros discursos, enunciações e enunciados.

O conjunto de regras para uma prática discursiva, o sistema de formação não é estranho ao tempo. Não reúne tudo que pode aparecer, através de uma série secular de enunciados, em um ponto inicial que seria, ao mesmo tempo, começo, origem, fundamento, sistema de axiomas, e a partir do qual as peripécias da história real só se desenrolariam de maneira inteiramente necessária. O que ele delineia é o sistema de regras que teve de ser colocado em prática para que tal objeto se transformasse, tal enunciação nova aparecesse, tal conceito se elaborasse, metamorfoseado ou importado [...] o que ele delineia, também, é o sistema de regras que teve de ser empregado para que uma mudança em outros discursos [...] pudesse ser transcrita no interior de um discurso dado, constituindo assim um novo objeto, suscitando uma nova estratégia, dando lugar a novas enunciações ou novos conceitos. ${ }^{33}$

32 FOUCAULT, Michel. A arqueologia do saber. Trad. Luiz Felipe Baeta Neves. Rio de Janeiro: Forense Universitária, 2012, p. 60.

33 FOUCAULT, Michel. A arqueologia do saber. Trad. Luiz Felipe Baeta Neves. Rio de Janeiro: Forense Universitária, 2012, p. 88. 
No lugar de partir na busca da origem desses saberes, problematizaremos tais práticas discursivas, buscando compreender de que maneira e em que ponto eles apareceram. Tal estudo toma a música como monumento para enxergar traçados dessa história.

\section{O Pampa e seu gaúcho herói}

Um campo a se estender imenso e plano, onde céu e campo se encontram. A região do Pampa foi cenário de múltiplos processos históricos e culturais (contando com a herança dos diversos povos que habitaram essas regiões, até nossos contemporâneos), o que contribuiu significativamente para a construção da cultura pampeana. Para entendermos sua geografia, bem como tais procedimentos culturais, trazemos sucintamente algumas considerações desse campo imenso que foi cenário/palco de grandes artistas que, por meio da música, ao longo dos tempos, vêm narrando esse espaço geográfico e cultural.

De acordo com Dos-Santos 34 "o pampa é horizonte do viver e das relações socioculturais de diversos povos que ali se encontraram ao longo dos anos, desde os indígenas até os nossos contemporâneos". Para o autor, ele é "peculiar e característica", pois carregamos a herança de nossas colonizações luso-espanhola, indígena, africana, alemã e italiana.

Região de terras planas conhecida também como região Platina, compreende parte do Rio Grande do Sul, da Argentina e a totalidade do Uruguai. $\mathrm{O}$ chamado campos do sul abarca uma área de

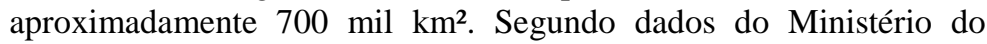
Meio Ambiente, só o estado do Rio Grande do Sul ocupa uma área equivalente a 176 mil $\mathrm{km}^{2}$. A região do Pampa é caracterizada por

34 DOS-SANTOS, José Daniel Telles. Lúcio Yanel e o Violão Pampeano: memória(s), história(s) e identidade(s) de um fazer musical no sul do Brasil. Dissertação (Mestrado) Universidade Federal de Pelotas, Programa de Pós-Graduação em Memória Social e Patrimônio Cultural, Pelotas, 2012, p. 51. 
uma vegetação composta por plantas rasteiras, árvores, serras, morros e coxilhas. Outra característica dessa região são os banhados, como o Banhado do Taim, localizado no sul do Rio Grande do Sul, bem como o Banhado de São Donato, situado entre os municípios de Itaqui e Maçambará, na fronteira com a Argentina, ambos reconhecidos como reservas ecológicas.

No que tange a questões culturais sobre o Pampa, na payada abaixo Braun $^{35}$ nos evidencia a forma como a música vem narrando.

Raízes, tronco, ramagem... Ramagem, tronco, raiz.../ Abriu-se uma cicatriz de onde brotei na paisagem.../ O tempo me fez mensagem que os ventos pampas dirigem / Dos anseios que me afligem de transplantar horizontes / Buscando o rumor das fontes pra beber água na origem. / Sobre o lombo da distância, de paragem em paragem / Fui repontando a mensagem de bárbara ressonância / Fazendo pátria na infância porque precisei fazê-la / E a Liberdade, sinuela, sempre foi a estrela guia / Que o meu olhar perseguia como quem busca uma estrela [...] / Primeiro era o campo aberto, descampado, sem divisas.../ Com fronteiras imprecisas, mundo sem longe nem perto... / Eu era o índio liberto, barbaresco e peleador / Rei de mim mesmo, senhor da natureza selvagem / A religião da coragem e o sol de bronze na cor / Um dia veio o jesuíta a este rincão do planeta / Vestindo a sotaina preta na catequese bendita / Foi mais do que uma visita à minha pampa morena / Bombeei por trás da melena, olhos nos olhos o irmão / E gravei no coração a santa cruz de Lorena! / Mais tarde veio mais gente às minhas terras campeiras.../ A falange das bandeiras, impiedosa e inclemente.../ Me levantei de repente e as tribos se levantaram.../ As várzeas se ensanguentaram, elas que eram verdejantes / Mas eu venci os bandeirantes, que nunca mais retornaram! / E depois vieram os lusos, os negros, os castelhanos / E nos

35 Jayme Caetano Braun (1924 - 1999) é considerado um dos nomes mais importantes da cultura gaúcha. Poeta e payador, Jayme Caetano Braun sempre ressaltou em suas poesias e payadas a vida campeira do gaúcho e sua relação com a paisagem pampeana. 
pagos campejanos, novas normas, novos usos... / As violências e os abusos da Ibéria, Castela e Lácio / Que rasgaram o prefácio e mataram as pegarias / E as ânsias [...] Sou o gaúcho que cresceu junto aos fortins de combate / $\mathbf{E}$ já estava tomando mate quando a pátria amanheceu!!! / E assim, crescendo ao relento, criado longe do pai / Junto ao mar doce - o Uruguai -, o rio do meu nascimento / Soldado sem regimento no quartel da imensidade... / Um dia me deu vontade, deixei crescer toda a crina / E me amasiei com uma china que chamei de Liberdade! / Por mais de trezentos anos fui pastor e sentinela / Na linha verde e amarela, peleando com castelhanos / Gravando com "los hermanos" a epopéia do fronteiro! / Poeta, cantor e guerreiro da América que nascia / A pátria é minha família! / Não há Brasil sem Rio Grande / E nem tirano que mande na alma de um Farroupilha! ${ }^{36}$

A Payada acima, de Jayme Caetano Braun, nos apresenta ditos bastante comuns a muitas canções pampeanas, como o amor por esta terra. As batalhas que o povo gaúcho lutou com tanta valentia são ressaltadas com muita altivez. Aqui está o orgulho de ser um farroupilha! Braun nos fala dos povos que aqui foram se achegando ${ }^{37}$ e colonizando o Rio Grande do Sul. Os portugueses, os espanhóis, os bandeirantes que vieram em busca dos índios para os escravizarem enfim, o payador nesta canção nos conta um pouco da história do Rio Grande do Sul. E esta é a importância que a música tem para a sociedade: uma prática cultural potente para pensarmos e problematizarmos diferentes acontecimentos que constituem nosso olhar para as coisas, para o mundo.

O início do século XVII no Rio Grande do Sul traz consigo a formação das primeiras reduções por padres jesuítas espanhóis que tinham como objetivo catequizar os índios guaranis. As primeiras reduções do lado da América Espanhola fundadas em território sul-

36 BRAUN, Jayme Caetano. Payada. Intérprete: Jayme Caetano Braun. In: JAYME CAETANO BRAUN. Payador. Brasil: Polyfar Discos do Brasil, 1983. Lado A. Faixa 1.

37 Termo de uso comum no Rio Grande do Sul. O mesmo que aproximar-se, achegar-se. 
rio-grandense se deram na região do Tape. Podemos dizer que foi nesse período que foram introduzidas, já na redução de São Miguel, as primeiras cabeças de gado, dando início a uma das características econômicas mais importantes do Rio Grande do Sul: a pecuária. Porém, o alargamento das Reduções nessa região despertou consideravelmente o ataque dos bandeirantes paulistas. Estes vinham em busca de índios para o comércio escravo, o que colocava em risco o projeto de cristianização dos índios por parte dos jesuítas. No entanto, por conta da superioridade dos bandeirantes paulistas, os jesuítas, juntamente com os guaranis, acabaram abandonando essa região e se estabelecendo do outro lado do rio Uruguai. Assim, o gado que havia sido introduzido acabou sendo abandonado nos vastos campos do pampa e, assim, multiplicando-se de forma desordenada. Em decorrência disso, uma desmedida reserva de gado que ficou conhecida como Vacaria del Mar deu início ao "fundamento econômico básico de apropriação da terra gaúcha: a preia do gado xucro". ${ }^{38}$

Este gado xucro que ficou conhecido como chimarrão, acabou tornando-se uma grande fonte de economia. Ou seja, ele era capturado com a finalidade de serem retirados o couro e a gordura para serem comercializados. A partir da Vacaria del Mar, a Redução de São Miguel prosperava e o interesse dos portugueses nessa região só aumentava. Foi com o intuito de se beneficiar desse gado que os portugueses fundaram em 1680 a Colônia de Sacramento, para exportarem, juntamente com os índios minuanos, o couro por Sacramento. É nesta região, localizada no planalto meridional, onde foram organizadas as primeiras estâncias missioneiras de gado.

Consideramos ser relevante destacar, mesmo que de forma sucinta, estas questões políticas e econômicas desenvolvidas no pampa, como a criação das estâncias de gado, pois no interior desses locais foram - e ainda são - produzidos discursos importantes que fazem parte da constituição do gaúcho. Além disso, nos parece importante colocar em suspenso estes acontecimentos históricos, como o ordenamento do gado nestas estâncias e as demarcações das

38 PESAVENTO, Sandra Jatahy. História do Rio Grande do Sul. $8^{\mathrm{a}}$ ed. Porto Alegre: Mercado Aberto, 1997, p. 9. 
terras como condições de proveniências para a fabricação do peão das fazendas. Através deste "ordenamento" do campo, da terra, da natureza e do gado, irrompe um gaúcho que deixa de ser aquele sujeito errante que Oliven ${ }^{39}$ nos anunciava, para tornar-se o "guardião" dos campos, das estâncias. Ainda assim, as lutas entre os portugueses e os espanhóis, além da peleia do índio missioneiro e o apreço que o mesmo tem por essas terras, estão em evidência em muitas canções pampeanas, como nos mostra a letra abaixo de Cenair Maicá $^{40}$.

Caminham guaranis pelas estradas / Trapos de gente se arrastando a pé / Restos da raça dos meus sete povos / Últimas crias do sangue de Sepé. / Fazem balaios de taquaras bravas / Em pobres ranchos que parecem ninhos / Onde se abrigam aves migratórias / A mendigar alguns mil réis pelos caminhos. / O balaio foi taquara, a taquara foi a lança / O balaio foi taquara, a taquara foi a lança, / Que esteiou os sete povos quando o pago era criança / Vão os índios pela estrada como aguapé pelos rios / Cantam ventos tristes nos seus balaios vazios, / Cantam ventos tristes nos seus balaios vazios. / Seguem os índios o destino peregrino dos sem terras / Tropeçando nos caminhos já sem luz / Afogados na fumaça do progresso / Junto aos animais em debandada. / Das florestas virgens violentadas / Pelos que vieram pelos que vieram sob o símbolo da cruz. I Quem os vê na humildade dos perdidos / Na senda amarga desses tempos novos / Não acredita que seu braço um dia / Levantou catedrais nos sete povos / Vende balaio o índio que plantava / Um novo mundo no império das missões / Balaios de taquara que eram lanças / Marcando a história das sete reduções. ${ }^{41}$

39 OLIVEN, Ruben George. A parte e o todo: a diversidade cultural no Brasil-nação. Petrópolis: Vozes, 1992.

40 Cenair Maicá (1947-1987) cantor e compositor gaúcho reconhecido por abordar os índios e a paisagem natural em suas canções.

41 MAICÁ, Cenair. Balaio, Lança e Taquara. Intérprete: Cenair Maicá. In: CENAIR MAICÁ. Canto dos Livres. Brasil, 1983. Lado A. Faixa 2. 
As guerras e batalhas pelas terras sul-rio-grandenses que a história nos demonstra desde a chegada de portugueses e espanhóis são evidenciadas na música pampeana, ainda na contemporaneidade. $\mathrm{Na}$ letra acima, Maicá nos fala da luta dos índios, "do sangue de Sepé" - índio este líder da Guerra Guaranítica, dos sete povos das missões que marcaram a história do Rio Grande do Sul. Índios, negros, portugueses, espanhóis, entre outros povos são marcas da cultura gaúcha que prevalece até os nossos dias.

A natureza do Pampa é muito evidenciada na música pampeana. Esta, muitas vezes, assume um lugar de destaque na obra de diversos compositores. Para Oliven ${ }^{42}$ a posição geográfica do Rio Grande do Sul, por ser uma região de fronteira, as atividades econômicas que foram e ainda são desenvolvidas no Estado, além de outros elementos "que evocam um passado glorioso" vão fabricando o sujeito gaúcho. E nessas representações que contribuem para a constituição do gaúcho, a natureza, muitas vezes, se faz presente. A historiografia, a literatura, as artes de uma forma geral nos apresentam uma vida marcada nos vastos campos do pampa, nas atividades campeiras, como a lida com o gado no lombo de um cavalo, enfrentando o calor do verão e o frio nas madrugadas do inverno. Enfim, ditos como esses são elementos potentes que nos fazem olhar para a história e problematizar a relevância da natureza para a constituição deste sujeito. Ou seja, a constituição do gaúcho é marcada pelas relações sociais, políticas, econômicas, culturais, geográficas e ambientais. Para Oliven ${ }^{43}$, esses acontecimentos que fazem parte da história do Rio Grande do Sul "[...] contribuem para a construção de uma série de representações em torno dele que acabam adquirindo uma força quase mítica que as projeta até nossos dias e as fazem informar a ação e criar práticas no presente". Para o autor, o gaúcho é um sujeito que tem na sua constituição as marcas da natureza, levando em consideração a vida campeira, ou mesmo as batalhas que enfrentou, tendo que lidar com as "forças naturais" de uma natureza muitas vezes "feroz". Muitas canções evidenciam a

42 OLIVEN, Ruben George. A parte e o todo: a diversidade cultural no Brasil-nação. Petrópolis: Vozes, 1992, p. 50.

43 OLIVEN, Ruben George. A parte e o todo: a diversidade cultural no Brasil-nação. Petrópolis: Vozes, 1992, p. 49. 
"força" e a "coragem" dos gaúchos de enfrentarem estes elementos naturais que constituem a natureza pampeana, como os ventos, as geadas, o calor e as chuvas, tanto nas batalhas em que lutou como na lida campeira. Seguindo nesta linha de argumentação, podemos pensar numa relação entre o homem e a natureza para a constituição desse gaúcho "marcado pela bravura que é exigida do homem ao lidar com as forças da natureza e a árdua vida campeira". ${ }^{44}$ Assim sendo, as grandes revoluções em que o povo habitante do Rio Grande do Sul lutou e a relação que o mesmo tem com a natureza na sua lida diária são importantes condições de possibilidade para a constituição desse sujeito guerreiro, herói, viril, leal, honrado, etc. Oliven ${ }^{45}$ nos diz ainda que "o gaúcho é socialmente um produto do pampa, como politicamente é um produto da guerra".

O Rio Grande do Sul se empenhou em uma constante batalha para pertencer ao Brasil. ${ }^{46}$ Quando portugueses e espanhóis disputavam estas terras, o Rio Grande do Sul optou por fazer parte do Brasil. Ainda, para o autor, existem alguns acontecimentos importantes que constituem o discurso do sul-rio-grandense e um deles é "[...] o alto preço pago por essa opção [...]". ${ }^{47}$ Em decorrência das condições físicas que constituem o espaço geográfico do Rio Grande do Sul, como as áreas litorâneas, os rios e as serras, fizeram que nosso Estado permanecesse por dois séculos separados do Brasil. Isto foi o que Oliven ${ }^{48}$ chamou de "o isolamento geográfico do Rio Grande do Sul”.

O Rio Grande do Sul é geralmente considerado como ocupando uma posição singular em relação ao Brasil. Isso se deveria às suas características geográficas, à sua

44 OLIVEN, Ruben George. A parte e o todo: a diversidade cultural no Brasil-nação. Petrópolis: Vozes, 1992, p. 49.

45 OLIVEN, Ruben George. A parte e o todo: a diversidade cultural no Brasil-nação.

Petrópolis: Vozes, 1992, p. 51.

46 OLIVEN, Ruben George. A parte e o todo: a diversidade cultural no Brasil-nação. Petrópolis: Vozes, 1992.

47 OLIVEN, Ruben George. A parte e o todo: a diversidade cultural no Brasil-nação. Petrópolis: Vozes, 1992, p. 49.

48 OLIVEN, Ruben George. A parte e o todo: a diversidade cultural no Brasil-nação. Petrópolis: Vozes, 1992, p. 47, p. 47. 
posição estratégica, à forma de seu povoamento, à sua economia e ao modo pelo qual se insere na história nacional. Apesar de o estado ter uma grande diferenciação interna (do ponto de vista geográfico, étnico, econômico e de sua colonização) ele é freqüentemente contraposto como um todo ao resto do país, com o qual manteria uma relação especial, a ponto de ser às vezes chamado jocosamente por outros brasileiros de "esse país vizinho e irmão do sul". ${ }^{49}$

\section{Na letra hino do Rio do Rio Grande do Sul, podemos evidenciar um pouco esta colocação de Oliven:}

Como aurora precursora /Do farol da divindade / Foi o vinte de setembro / O precursor da liberdade / Mostremos valor constância / Nesta ímpia injusta guerra / Sirvam nossas façanhas / De modelo a toda terra / De modelo a toda terra / Sirvam nossas façanhas / De modelo a toda terra / Mas não basta pra ser livre / Ser forte, aguerrido e bravo / Povo que não tem virtude / Acaba por ser escravo / Mostremos valor constância / Nesta ímpia injusta guerra / Sirvam nossas façanhas / De modelo a toda terra / De modelo a toda terra / Sirvam nossas façanhas / De modelo a toda terra. ${ }^{50}$

Uma "ímpia e injusta guerra" e, assim, "Sirvam nossas façanhas / De modelo a toda terra / De modelo a toda terra" - O hino sul-rio-grandense é uma insígnia de nosso Estado, assim como a bandeira do Rio Grande do Sul, que tem seu lema "Liberdade, igualdade e humanidade", inspirado nos ideais da Revolução Francesa (1789-1799). É a partir da Lei Estadual 5213 de 1966 que ambos

49 OLIVEN, Ruben George. A parte e o todo: a diversidade cultural no Brasil-nação. Petrópolis: Vozes, 1992.

50 FONTOURA, Francisco Pinto da. Hino Republicano. In: PORTO ALEGRE, Apolinário José Gomes. Cancioneiro da revolução de 1835. Porto Alegre, Companhia União de seguros, 1981. 
passam a ser símbolos importantes na/da cultura do Rio Grande do Sul, herdados da Revolução Farroupilha.

No transcorrer deste estudo, vimos pontuando alguns acontecimentos discursivos importantes da/na história do Rio Grande do Sul, para que possamos apreender as condições históricas de nossa situação presente. A partir dos nossos estudos sobre a Revolução Farroupilha, bem como do nosso corpus discursivo (letras de música), pudemos constatar o quanto a fabricação de um sujeito herói está também atrelada aos "heróis" da Revolução Farroupilha. Segundo Oliven $^{51}$, esse status atribuído ao gaúcho como um sujeito herói foi se dando gradativamente. O gaúcho era tido/visto como um marginal, um ladrão de gado até meados do século XIX. Portanto, com as demarcações das estâncias, o aparecimento de novas raças de gado, entre outras coisas, este sujeito passa a ser considerado um homem gentílico, um peão de estância. A historiografia tradicional nos apresenta este tipo "especial" de sujeito como uma figura peculiar do Pampa Gaúcho. Para Salaini ${ }^{52}$ "A figura simbólica do gaúcho é representada pelo homem da campanha que teve na Revolução Farroupilha o cenário para as suas façanhas e heroísmos". Corroborando com esta colocação, Pesavento diz ainda que Bento Gonçalves, um dos líderes da Revolução, é

[...] considerado, pela historiografia tradicional como o herói do movimento, corporificando todas as virtudes típicas do homem rio-grandense. $\mathrm{Na}$ verdade, a atribuição do status de herói a Bento Gonçalves se insere mais uma vez na tendência da historiografia oficial de reconstruir o passado de uma forma idealista. Neste sentido, a Revolução Farroupilha, pontilhada de lances militares audazes, foi o tema de grande predileção dos historiadores rio-grandenses, onde a heroicidade do

51 OLIVEN, Ruben George. A parte e o todo: a diversidade cultural no Brasil-nação. Petrópolis: Vozes, 1992.

52 SALAINI, Cristian Jobi. “Nossos heróis não morreram”: um estudo antropológico sobre as formas de "ser negro" e de "ser gaúcho" no estado do Rio Grande do Sul. Dissertação (Mestrado). Universidade Federal do Rio Grande do Sul. Instituto de Filosofia e Ciências Humanas. Programa de Pós-Graduação em Antropologia Social. Porto Alegre, RS, 2006, p. 41. 
gaúcho encontraria respaldo nas figuras de Bento Gonçalves, Davi Canabarro, Antônio de Souza Netto, etc. ${ }^{53}$

De acordo com a autora, poder-se-ia dizer que o gaúcho tem, na sua constituição enquanto sujeito herói, características que nos remetem aos estancieiros rio-grandenses que lutaram na Revolução Farroupilha em busca de uma maior autonomia política para o Estado. No entanto, este sujeito idealizado, figura simbólica do Estado do Rio Grande do Sul, é também encontrado na literatura pampeana, a partir de autores como Érico Veríssimo, Barbosa Lessa, João Simões Lopes Neto, entre outros. Oliven ${ }^{54}$ contribui ao ressaltar que as representações em torno desse sujeito se fazem ainda presentes nas narrativas de viajantes estrangeiros como Saint-Hilaire e Arsène Isabelle, bem como na literatura romântica de José de Alencar, principalmente com o livro "O Gaúcho", publicado em 1870. Diante de tais considerações, podemos ressalvar que não há uma origem, um momento ou local específico para a emergência deste sujeito gaúcho herói. Ou seja, as representações em torno desse sujeito vêm sendo fabricadas a partir de diferentes contextos sociais, políticos, artísticos e culturais. O culto em torno da figura do gaúcho apresenta peculiaridades que os distinguem de outros tipos de sujeito, como os nordestinos e os habitantes do centro-sul do Brasil ${ }^{55}$. Para o autor, essas diferenças "[...] seriam causadas pelo meio ambiente e pela superioridade política provinda da experiência de guerra [...]".56

Embora o Rio Grande do Sul se apresente como heterogêneo, a historiografia, da mesma maneira que o tradicionalismo gaúcho, tende a conceber os sul-rio-grandenses a partir de "[...] um único tipo social: o gaúcho, o cavaleiro e peão de estância da região sudoeste do

53 PESAVENTO, Sandra Jatahy. História do Rio Grande do Sul. $8^{\mathrm{a}}$ ed. Porto Alegre: Mercado Aberto, 1997, p. 46.

54 OLIVEN, Ruben George. A parte e o todo: a diversidade cultural no Brasil-nação. Petrópolis: Vozes, 1992.

55 OLIVEN, Ruben George. A parte e o todo: a diversidade cultural no Brasil-nação. Petrópolis: Vozes, 1992.

56 OLIVEN, Ruben George. A parte e o todo: a diversidade cultural no Brasil-nação. Petrópolis: Vozes, 1992, p. 51. 
Rio Grande do Sul" ${ }^{57}$ No que tange a música tradicionalista esta tem uma importância significativa para a cultura pampeana. Por meio dela, muitas disputas se travaram e ainda se travam em torno da construção e fabricação dos sujeitos que habitam essas terras. Os modos de ser e viver (tantas vezes pautados no homem da campanha, tendo como cenário o campo) vão constituindo um modo de olhar e se relacionar com a natureza. Assim, nas palavras de Luís Agostinho Agostini,

[...] A música tradicionalista atualiza o mito, à medida que os festivais e outras manifestações musicais se sucedem, ano após ano. Através da apropriação de imagens simbólicas já cristalizadas no imaginário social, percebe-se que a música tradicionalista ajuda a ordenar a sociedade sul-rio-grandense, imprimindo regras e valores essenciais à identidade que o gaúcho ostenta e da qual parece não querer se desfazer. ${ }^{58}$

Os significados que vêm sendo fabricados e atribuídos aos habitantes do Rio Grande do Sul tem suas condições de proveniência no homem da campanha, no peão de estância, no guerreiro que ao longo do tempo vem defendendo a sua terra. Isso pode ser observado na historiografia, na literatura, na música, etc. Como já salientado anteriormente, o gaúcho tal qual conhecemos hoje, este sujeito herói que vimos evidenciando, nem sempre teve o significado de sujeito gentílico.

No período colonial, o habitante do Rio Grande do Sul era chamado de guasca e depois de gaudério, este último termo possuindo um sentido pejorativo e referindo-se aos

57 OLIVEN, Ruben George. A parte e o todo: a diversidade cultural no Brasil-nação. Petrópolis: Vozes, 1992, p. 50.

58 AGOSTINHO, Luís Agostini. O Pampa na cidade: o imaginário social na música popular gaúcha. Dissertação (Mestrado). Universidade de Caxias do Sul. Programa de Mestrado em Letras e cultura Regional, Caxias do Sul, RS, 2005, p. 67. 
aventureiros paulistas que tinham desertado das tropas regulares e adotado a vida rude dos coureadores e ladrões de gado. Tratava-se de vagabundos errantes e contrabandistas de gado numa região onde a fronteira era bastante móvel em função dos conflitos entre Portugal e Espanha. No final do século XVIII, eles são chamados de gaúcho, vocábulo que tem a mesma conotação pejorativa até meados do século XIX, quando, com a organização da estância, passa a significar o peão e o guerreiro com um sentido encomiástico. ${ }^{59}$

Ante tais colocações, não temos a pretensão de determinar juízo de valores, tampouco definir o certo e/ou errado, a verdade e/ou a mentira. Ansiamos problematizar o quanto esses discursos fabricados na cultura que, atrelados a relações de força, fazem emergir verdades e saberes pouco problematizado por muitos de nós. Ainda na contemporaneidade, diferentes artefatos culturais (como a música pampeana) evidenciam em muitas canções este sujeito herói, um sujeito que "brilhou" e lutou com toda "garra" pelo Rio Grande do Sul. Como ressalta Silva ${ }^{60}$ esses "homens saíram da História para entrar no mito". E nos diz ainda que esses sujeitos:

Hoje, brilham em livros escolares ou figuram em placas de ruas paradoxalmente esquecidos e sempre lembrados. Quem foram esses homens? O que fizeram? Foram somente heróis? E se tivessem sido também infames personagens de uma época cruenta em que o futuro se fazia a golpes de preconceitos, de lanças e de balas de canhão? ${ }^{61}$

59 OLIVEN, Ruben George. A parte e o todo: a diversidade cultural no Brasil-nação. Petrópolis: Vozes, 1992, p. 50.

60 SILVA, Juremir Machado da. História regional da infâmia: o destino dos negros farrapos e outras iniqüidades brasileiras (ou como se produzem os imaginários). Porto Alegre, RS: L\&PM, 2010, p. 13.

61 SILVA, Juremir Machado da. História regional da infâmia: o destino dos negros farrapos e outras iniqüidades brasileiras (ou como se produzem os imaginários). Porto Alegre, RS: L\&PM, 2010, p. 13. 
Ao ressaltar as colocações e questionamentos do autor, não nos interessa aqui desvendar quem foram esses homens, nem revelar se foram ou não heróis. Evidenciamos o quanto esses ditos fabricados na cultura nos subjetivam, nos educam e, muitas vezes, determinam nossos modos de ser e de pensar.

A Revolução Farroupilha é considerada como um dos feitos mais "gloriosos" dos gaúchos. Tal acontecimento é lembrado e festejado anualmente na semana de 20 de setembro (dia e mês da Revolução) pelo Estado Rio Grande do Sul. Durante uma semana acontecem desfiles a cavalo nas ruas das cidades, encontros nos CTGs (Centro de Tradição Gaúcha) com danças, músicas, comidas e bebidas típicas do gaúcho para celebrarem a cultura e a tradição dos rio-grandenses. Para Zalla e Menegat este episódio da história do Estado

[...] se configurou, historicamente, como um evento emblemático da memória pública no Rio Grande do Sul. Seus lances de batalha são, ainda hoje, narrados em tom épico, e seus protagonistas transformados em heróis da 'pequena' e da 'grande pátria, ora pela suposta resistências à opressão do centro político e econômico do Brasil, ora pela também hipotética aspiração à liberalização e 'republicanização' do país, o que incorre na afirmação de seu caráter nacionalista. Em ambos os sentidos, como mito, a revolta tem sido matriz para discursos políticos, debates historiográficos, criações artísticas e projetos identitários'. ${ }^{62}$

De acordo com os autores, a Revolução Farroupilha deixou marcas muito fortes em nosso Estado. Como vimos mostrando, este episódio está ainda muito presente na memória do sul-rio-grandense. Esta batalha de caráter republicano travada contra o governo imperial é deveras enaltecida pela música pampeana. "Seus lances de batalha", 
"seus protagonistas transformados em heróis", a natureza, a bravura com que o negro lutou, são enunciações recorrentes em muitas canções. O Pampa, espaço geográfico e cultural de muitas batalhas, este "[...] romântico deserto verde dos cavaleiros errantes e peões das imensas estâncias" ${ }^{63}$, são ditos importantes para pensarmos e problematizarmos na fabricação deste sujeito atrelado a uma também fabricação da natureza. No entanto, ora selvagem, ora romântica, como ressaltam os autores. É um emaranhado de ditos que compõem essa trama discursiva em torno dessa natureza e do sujeito gaúcho. $\mathrm{Na}$ canção abaixo de Teixeirinha ${ }^{64}$, apresentamos uma letra que nos fala da "beleza" do Rio Grande, do seu céu azul, das lutas, do orgulho de ter nas veias "o sangue herói de Farrapos".

Quem quiser saber quem sou / Olha para o céu azul / E grita junto comigo / Viva o Rio Grande do Sul / O lenço me identifica / Qual a minha procedência / Da província de São Pedro / Padroeiro da querência / Ó meu Rio Grande de encantos mil / Disposto a tudo pelo Brasil / [...] Berço de Flores da Cunha / E de Borges de Medeiros / Terra de Getúlio Vargas Presidente brasileiro. Eu sou da mesma vertente / Que Deus saúde me mande / Que eu possa ver muitos anos / O céu azul do Rio Grande / Te quero tanto torrão gaúcho / Morrer por ti me dou no luxo. [...] Meu coração é pequeno / Porque Deus me fez assim / O Rio Grande é bem maior/ Mas cabe dentro de mim. Sou da geração mais nova / Poeta bem macho e guapo / Nas minhas veias escorre / O sangue herói de Farrapos / Deus é gaúcho de espora e mango / Foi maragato ou foi chimango / Querência amada, meu céu de anil / Este Rio Grande gigante / Mais uma estrela brilhante na bandeira do Brasil. ${ }^{65}$

63 ZALLA, Jocelito; MENEGAT, Carla. História e memória da Revolução farroupilha: breve genealogia do mito. Revista Brasileira de História. São Paulo, v. 31, nº 62, p. 49-70, 2011, p. 50.

64 Teixeirinha cantor e compositor gaúcho considerado um dos representantes da música tradicionalista gaúcha.

65 TEIXEIRINHA. Querência Amada. Intérprete: Osvaldir e Carlos Magrão. In: OSVALDIR E CARLOS MAGRÃO. Querência Amada. Brasil, 1997. 1 CD. Faixa 2. 
Como nos evidencia a letra acima, há nos rio-grandenses um orgulho de ser gaúcho. Esta é uma "Querência amada" pelo seu povo, uma terra "de encantos mil", um "Rio Grande gigante" herdeiro da Revolução Farroupilha. Segundo Pesavento ${ }^{66}$, a fabricação discursiva a respeito deste episódio e a representatividade que o mesmo tem para cultura e para a história do Rio Grande do Sul estariam pautadas em uma tendência idealista, pois

[...] os arautos da historiografia regional celebraram os feitos de seus "heróis" e visualizaram esse prolongado conflito da província contra o Império como uma verdadeira epopéia. É claro que a longa duração do conflito (1835-1845) e o oferecimento de uma "paz honrosa" no final da guerra, sem que os farrapos tivessem sido vencidos no campo de batalha, foram elementos muito fortes para a construção do mito ou para a idealização do movimento. ${ }^{67}$

A autora diz ainda que, para a historiografia tradicional, a Revolução Farroupilha foi erigida como um acontecimento que sempre denotou a bravura, o heroísmo do gaúcho. Diante destas idealizações é que vem se fabricando este sujeito marcado pela coragem e pelo seu heroísmo. Tal produção discursiva vem sendo reverberada por historiadores desde o início do século com o intuito de perseverar a dominação do setor agropecuário do Rio Grande do Sul. Ou seja, todo esse imaginário diante da Revolução estaria atrelado a um momento de crise da economia pecuarista sul-riograndense que via na "reelaboração do seu passado [...] fatos que os nobilitassem e desta forma justificassem seu predomínio na sociedade". ${ }^{68}$

66 PESAVENTO, Sandra Jatahy. História do Rio Grande do Sul. $8^{\mathrm{a}}$ ed. Porto Alegre: Mercado Aberto, 1997, p. 7-8.

67 PESAVENTO, Sandra Jatahy. História do Rio Grande do Sul. $8^{\mathrm{a}}$ ed. Porto Alegre: Mercado Aberto, 1997, p. 7-8.

68 PESAVENTO, Sandra Jatahy. História do Rio Grande do Sul. $8^{\mathrm{a}}$ ed. Porto Alegre: Mercado Aberto, 1997, p. 8. 
Conforme salienta Kühn ${ }^{69}$ “[...] como nenhum outro conflito da história do Rio Grande do Sul, a Guerra dos Farrapos foi fundamental para a constituição da própria identidade rio-grandense". Vale ressaltar aqui, que não trabalhamos com o conceito de identidade, termo este bastante utilizado na historiografia regional para apreender a constituição do gaúcho. Nossa pesquisa versa segundo uma perspectiva foucaultiana, onde o filósofo opera com o conceito de posições de sujeito. O pensamento de Foucault trava uma busca no "entendimento acerca dos processos pelos quais os indivíduos se tornam sujeitos como resultado de um intricado processo de objetivação que se dá no interior de redes de poderes que os capturam, dividem, classificam". ${ }^{70}$ Ainda para o autor, o poder é um elemento importante para nos fazer apreender como se fabricam os saberes que em determinados contextos históricos, sociais, políticos, econômicos e culturais nos constituem enquanto sujeitos de um tempo. Para isso, estamos olhando para a Revolução Farroupilha.

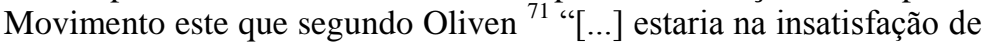
estancieiros em relação à excessiva centralização política imposta pelo governo central e no sentimento que a província era explorada economicamente pelo resto do Brasil". Silva ${ }^{72}$ complementa ao ressaltar que, além da disparidade das taxas cobradas sobre o charque rio-grandense e o charque uruguaio, uma das principais causas da Guerra teria sido "[...] a independência da Banda oriental, a Cisplatina, o Uruguai, em 1828". Para o autor, com a independência do Uruguai, os estancieiros rio-grandenses que possuíam terras no Uruguai não teriam mais livre acesso a esses campos, que a partir de então, seriam de nossos Hermanos do Prata. Segundo os fazendeiros da época, os campos uruguaios eram considerados superiores às terras

69 KÜHN, Fábio. Breve História do Rio Grande do Sul. Porto Alegre: Leitura XXI, 2011 , p. 75 .

70 VEIGA-NETO, Alfredo. Foucault e a Educação. 2 ed. 1 reimp. Belo Horizonte: Autêntica, 2007, p. 55.

71 OLIVEN, Ruben George. A parte e o todo: a diversidade cultural no Brasil-nação. Petrópolis: Vozes, 1992, p. 57.

72 SILVA, Juremir Machado da. História regional da infâmia: o destino dos negros farrapos e outras iniqüidades brasileiras (ou como se produzem os imaginários). Porto Alegre, RS: L\&PM, 2010, p. 50. 
rio-grandenses, o que consequentemente prejudicaria o setor pecuarista em terras sulinas.

Aqui procuramos evidenciar algumas das condições de proveniência e emergência de um gaúcho tomado como herói e seus atravessamos na composição de uma natureza bela e romântica nas letras de muitas músicas pampeanas. Diante desses recortes de acontecimentos que trouxemos, importa destacar que não há um ponto específico de "surgimento" desse sujeito tão enaltecido pela música sul-rio-grandense. Assim, ressaltamos a importância de colocarmos em suspenso nossas verdades mais sólidas... Verdades essas inventadas em um determinado tempo e lugar e que nos capturam e nos constituem enquanto sujeitos gaúchos.

\section{Breves considerações}

Este artigo pretendeu evidenciar a importância da história como uma potente ferramenta foucaultiana. Pontuamos uma breve contextualização sobre o Rio Grande do Sul, como a constituição das estâncias de gado, as questões culturais sobre o Pampa, a fabricação de um sujeito gaúcho herói atrelado à fabricação de uma natureza. Como vimos demonstrando, o gaúcho é um amante da natureza - ele a enaltece em suas obras artísticas - e isso de uma forma bela e romântica. No entanto, vale ressaltar que quando esta é referenciada na historiografia, na difícil lida campeira a qual o gaúcho tem que enfrentar, a natureza é, muitas vezes, selvagem. Ora, ao mesmo tempo em que a natureza nos beneficia com um espaço geográfico propício a fins econômicos e políticos no que diz respeito às atividades rurais exercidas pelo homem do campo como uma terra produtiva, este espaço físico nos contempla também com um emaranhado de elementos naturais e climáticos que deveriam ser "dominados".

RECEBIDO EM: 16/01/2017 APROVADO EM: 19/06/2017 